\title{
Silage Feeding with Water Hyacinth in the Tropics: A Research Note
}

\author{
Danny Agustin Flores \\ Skye Blue Internet, Port Coquitlam, Canada \\ Email: dannflores5@aim.com
}

How to cite this paper: Flores, D.A. (2022) Silage Feeding with Water Hyacinth in the Tropics: A Research Note. Agricultural Sciences, 13, 282-289.

https://doi.org/10.4236/as.2022.132019

Received: December 12, 2021

Accepted: February 22, 2022

Published: February 25, 2022

Copyright $\odot 2022$ by author(s) and Scientific Research Publishing Inc. This work is licensed under the Creative Commons Attribution International License (CC BY 4.0).

http://creativecommons.org/licenses/by/4.0/ (c) (i) Open Access

\begin{abstract}
Water hyacinth has ecological significance in addition to its agricultural and energy uses. Lower quality silage is defined in this paper as requiring nitrogen supplementation and treatment to improve nutritive value (NV). Ensilage of water hyacinth as a test case centers largely around the process to optimize protein nitrogen retention in silage-based regimens. A previous hypothesis proposed earlier by the author of that of functional amino acid ratios [tyrosine (TYR): large neutral amino acids (LNAA), tyrosine (TYR): phenylalanine (PHE)] were subsequently found to be counter to what the given schemata predicts. And subsequently with another study there was no corroborative evidence for it to support the espoused hypothesis using the same schemata. The role of $\mathrm{N}$ status is still the most viable option among factors from studies continuing how amino acids like histidine (HIS) and arginine (ARG) and their growth-related endocrine functions play a role. There are other schemas illustrating non-homeostatic type regulation with protein intake. To focus on molecular-level mechanisms to ruminal protein digestion it is becoming clear what factors in feed and microbial cell fermentation contribute to optimizing microbial cell protein (MCP) synthesis from ATP with organic matter (OM) digestibility and preformed amino acids (PFAA) from peptides and free amino acids in addition to non-protein nitrogen (NPN), the former more efficiently assimilated in MCP than NPN in the rumen. Accordingly, it has been recommended that soluble proteins fed to dairy cows not exceed microbial requirements along with high dietary escape protein fed with a sufficient amino acid profile to meet dairy production.
\end{abstract}

\section{Keywords}

Water Hyacinth, Lower Quality, Silage, Functional Amino Acids, Nitrogen Status, Nutritive Value 


\section{Introduction}

Water hyacinth (Eichhornia crassipes) is a fresh water floating aquatic weed or plant and ecologically can potentially choke waterways and overgrow in lakes and ponds and has also multiple uses for pollution detoxification of heavy metals, pesticides and waste treatment in general, used in fertilizer amendments, and agricultural and energy applications such as livestock feeding with either dried or wet ensiled forms for the former with pigs, poultry and fish and the latter with cattle and finally for biofuel feedstock as with biofermentation for bioethanol generation.

This paper introduces tropical silage-making for feedstuffs being utilized or as still being proposed. For a definition of lower quality silages as defined here, it is one that needs nitrogen $(\mathrm{N})$ supplementation and could require other interventives such as protein and/or energy concentrate supplementation, chemical (propionic, acetic and formic acids) and/or biological treatment (wilting or field drying) in order to improve the basal residue's digestibility in the ration, and the dry matter intake (DMI) from increased physical digestibility in the rumen stomach and resulting in boosted microbial cell protein (MCP) synthesis. Overall there is an increase in nutritive value (NV).

\section{Ensilage in the Tropics: The Test Case for Water Hyacinth in Feeding}

A description of the test case for water hyacinth feeding already practiced in the Philippine Islands follows.

Ensilage is recommended for feeding as a need for mechanization for easier handling, harvesting/chopping, processing with chemical/biological treatments, proper storage in a silo, for e.g.: below ground level, in a stack silo or covered shed silo, and preservation to a stable biomass ideally due to rapid acidification relatable as a function to osmolality (high osmotic pressure or lower water activity, $\mathrm{Aw}$ ) and low silage $\mathrm{pH}$ from fermentable sugars in the forage biomass and allowing for year round feeding for both the wet and dry seasons.

Feeding regimens involve grass silage or corn silage although adaptation is possible with wholly feeding aquatic plants, e.g. water hyacinth, which becomes palatable overtime. This could be due to improved protein digestion and $\mathrm{N}$ status with the resulting intake.

There can be heavy soil contamination occurring requiring washing of the fresh plant bio mass. Before ensiling there is also the need to press feed material and reduce water content to about $50 \%$, as otherwise the ensiling biomass would have significant run-off with loss of nutrients especially in a vertical stack silo.

Additive feed recommendations with aquatic plant silages may include for e. g.: citrus pulp, cracked yellow corn or grain, molasses from sugarcane and organic acids added at a rate of $2 \%-4 \%$ including propionic and acetic acids (8:2 ratio) and also formic acid. Again, focus is with rapid acidification and adequate protein retention of feed biomass. 
It should be noted that where palatability is involved with different animal factors coming into play as with different animal classes: dairy cows, steers and sheep. Also grasses and legumes may or may not be comparable in quality due to the fact that aquatic plant species can be higher in digestibility.

A diet of paddy straw and water hyacinth silage supplemented with nitrogen (N) such as from legumes, ground nut cake, fishmeal, rice bran, copra meal and cornmeal are a viable feed source for meat and dairy animals especially where feed resources are scarce and making use of such feed byproducts more of a possibility. It should be added that paddy straw, aquatic plants and SCT feeding regimens be further investigated as promising feed resources for dairy in future.

\section{Functional Amino Acids (FAA) and Their Role with Nitrogen (N) Status and Intake Control}

The information from the scientific literature on water hyacinth is only paucitous at this time. Therefore the paper will use grass and/or legume silage as a model system for illustrating various biochemical changes occurring during the ensiling fermentation process.

In the following of two earlier studies on functional amino acids (FAA), in particular, in relation to the animal's intake response reference is made to that of [1] [2]. Inventory of the resulting data from both studies reveal that based on the schema (see: Figure 1) there is an inverse relationship between ratios of tyrosine:large neutral amino acids (TYR/LNAA) and more specifically of tyrosine to phenylalanine (TYR/PHE) and the resulting plasma amino acid ratios in ovine in the study agree with the schemata in Figure 1 for intake control in inverse relationship for both plasma ratios with the $19 \%$ higher intake on the fresh (frozen) control versus ensiled treatment.

The use of silage in the tropics, referring specifically to aquatic plants like water hyacinth, refers to a central concern of protein retention of the ensiled biomass and that previously the role of certain FAA has not come to fruition in explaining the intake response that is attributable to non-homeostatic control in

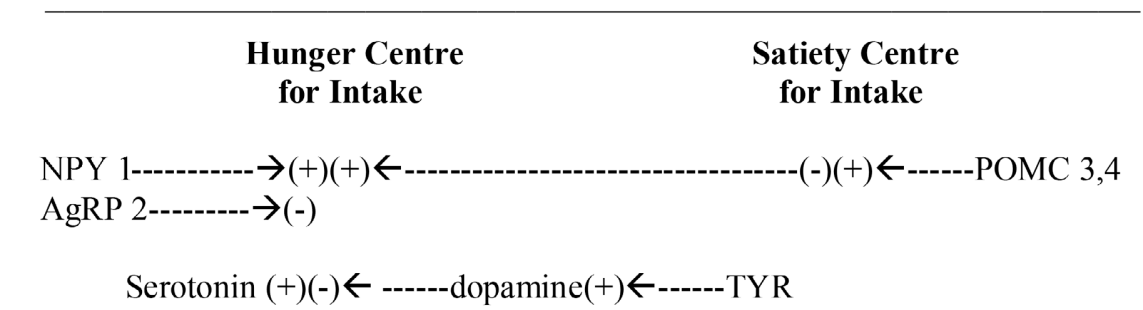

$1 \mathrm{NPY}=$ neuropeptide $\mathrm{Y}$

$2 \mathrm{AgRP}=$ agouti-response protein

3 POMC= proopiomelanocortin

4 Neurons in the arcuate nucleus

Figure 1. Schemata for homeostatic control of feed intake. 
nature where TYR is involved specifically as precursor to dopamine antagonizing serotonin for the hunger drive in that center while other FAA pertain to hormonal secretion of hGRH/hGH leading to LBM accretion/fat loss.

The factors in the rumen stomach of animal livestock have been elucidated and related to amino acids supplied as peptides and transported into the microbial cell and that are resynthesized as protein intracellularly with greater efficiency under optimal rumen fluid concentrations from feed protein microbial digestion and that leads to ruminal escape of that part of that feed fraction.

There is data from human studies illustrating what is called acute TYR/PHE depletion (or ATPD) to investigate the effect of reduced dopamine function on appetite and the reward value of food in human health volunteers where participants reported significantly lower levels of hunger following a fixed test meal relative to the balanced amino acid mixture of control meal. In conclusion, they found no evidence in humans for compensatory eating following ATPD [3].

It is suggested for more study of the ATPD condition with livestock which involves infusions of amino acid mixtures to induce it together with measurements of the animal's ad lib intake response and the plasma levels for amino acid ratios of interest here.

In studies [4], the infusion of PHE, histidine (HIS) and leucine (LEU) on basal GH levels and growth human releasing hormone (GHRH)-stimulated GH levels. A trend toward an increase in basal GH levels was found after HIS infusion while HIS and LEU did not significantly modify either basal or GHRH-induced GH secretion, and with arginine (ARG) also increased basal and GHRH-stimulated GH levels.

Mentioned here in passing is also a need for radioimmunoassay studies for livestock with bovine growth releasing hormone (bGRH) and bovine growth hormone (bGH) and muscle accretion with fat depletion measurements with a resulting leaner carcass to investigate further the effect of functionality of amino acids in this way.

In another study with [5], demonstrated that intravenous infusions of glucose and certain amino acids increased both nitrogen balance and muscle accretion; co-infusion of glucose and essential amino acids would act to additively improve $\mathrm{N}$ balance by decreasing muscle protein degradation in association with alterations in muscle expression of components of the ubiquitine-proteasome proteolytic pathway.

With a study of [6], there was a report of an erratum accompanying the $\mathrm{N}$ balance dataset comparing it with intake, which could not consider the data reported in order to correlate directly $\mathrm{N}$ balance and intake. But the author reports with other research studies on indicators related as a \% of controls, a marked difference for intake response in direct relationship with respect to $\mathrm{N}$ status indicators (see: Table 1).

\section{Non-Regulated versus Homeostatic Control of Intake}

Before leaving the study of (2) used for illustrating finds on intake control of 
Table 1. Manipulation of amino acid flows to the intestines of sheep fed low-quality diets.

\begin{tabular}{ccccc}
\hline & \multicolumn{4}{c}{ Parameterization } \\
\cline { 2 - 5 } Basal Diet & Supplementation & $\begin{array}{c}\text { Intake } \\
(\% \text { control) }\end{array}$ & $\begin{array}{c}\text { Correlates with } \\
\text { N Status (\%control) }\end{array}$ & Source \\
\hline Hay & Starch sprayed onto Forage & $111^{\mathrm{b}}$ & $267^{\mathrm{a}, \mathrm{c}}$ & {$[7]$} \\
Semi-purified, urea as N source & Casein infusion & 237 & $280^{\mathrm{c}}$ & {$[8]$} \\
Silage & Feeding protected Casein & $158^{\mathrm{b}}$ & $400^{\mathrm{a}, \mathrm{c}}$ & {$[9]$} \\
Silage & Fresh versus Ensiled & 123 & $127^{\mathrm{a}, \mathrm{d}}$ & {$[1][2]$} \\
\hline
\end{tabular}

a Resulted in increased flow to the duodenum. ${ }^{\mathrm{b}}$ Basal feed intake. ${ }^{\mathrm{c}} \mathrm{N}$ retention. ${ }^{\mathrm{d}}$ Data adapted from [10].

silage diets, we should further elaborate their definitions as utilized to demonstrate the various states of control or non-regulatory control of the livestock's response.

Three states with respect to protein status that can be defined are: 1) the low protein deficient diet, 2) imbalanced amino acid levels fed from their formulated mixtures where one or more amino acids are deficiently low, and 3) slightly imbalanced in the diet and tending to be also low. In the study of the author there was a pattern in both daily duodenal supplied amino acid flows and accompanying postprandial plasma levels which was seen to be deficient [1] [2]. Contrary to homeostatic control involving different levels of animal $\mathrm{N}$ status and their associated intake response they constitute the opposite metabolic case we term here as non-regulatory. As mentioned in the case of cause and effect in homeostatic control a feedback loop exists between the liver's $\mathrm{N}$ status and the vagus nerve to the animal's central nervous system (CNS).

\section{Possible Molecular Mechanisms to Rumen Digestion of Plant Feeds}

To study the MCP plus escape protein/energy output of biomass from the specialized rumen stomach of dairy cows, considered is the microbial cell growth and original plant material that escapes from feed substrate digested in the rumen instead.

There may be a theoretical basis for studying factors that could help determine the efficiency and action of MCP synthesis. These have been pointed out to be aspects of microbial cell biochemistry and physiology: 1) as with membrane transport processes and their rates, 2) mitogenesis or rate of cell division as possible functions of ATP, NADPH, THF, and B12 with respect to DNA synthesis, 3) apoptosis or cell death such as fructan oligosaccharides (FOS) which have been related to TNF-alpha and cell death in equine, 4) uncoupling of microbial energetic efficiency and 5) a suggestion using general mechanism analogical to that of mTOR cell signaling in higher cells, for e. g., with the amino acid leucine (LEU) resulting in increased protein synthesis and decreased proteolysis.

To point out the following factors that figure in the plant material as substrate 
for microbial digestion and growth are: 1) ligneous components in feed material and the subsequent digestibility of plant fibre, 2) boosting fructan content and other water-soluble carbohydrates (WSC), 3) plant protease activity in crops and resulting preformed amino acid "pools" and peptide availability in the rumen to microbes and also in respect to synthesis of limiting essential amino acids in microbial cell metabolism.

\section{The Efficiency of Microbial Cell Protein (MCP) Synthesis}

The hypothesis as stated here by the author draws from the following: 1) peptides are transported with differing rates with an ATP energy supply for transport, 2) the energy used for incorporating amino acids from peptides consume less ATP than from free amino acids to MCP and 3) protein that is optimally less degradable and released during proteolysis and taken up is more efficiently used for MCP synthesis.

To outline some areas for further research on the efficiency of microbial protein synthesis, for e.g., using sheep and their rumen stomachs: 1) transport processes and rates of pre-formed amino acids (PFAA) (i.e. amino acids + peptides) through the cell membrane, and the 2) uncoupling with bacterial cells, is due to the energetic efficiency which occurs differentially under energy-limiting conditions [11], and could be used as basis for further studies into feed substrate and their availability regards efficiency and yield for MCP biomass in the rumen.

It is proposed again here that forage heat-treatment or damage (e.g. with steam treatment or by wilting) provides a higher supply of nitrogen $(\mathrm{N})$-containing substrates to rumen micro-organisms, in relation to energy availability and from carbohydrate degradation due probably to their reduced protein solubility and proteolysis [12], at a given dilution rate $(\% / \mathrm{hr})$. It is conjectured that the rate of proteolysis is optimized which otherwise results in loss from excess deamination to ammonia-N following the re-uptake of the ammonia-N and PFAA-N.

Studies consistent with the previously held hypothesis are the kind by Lee Baldwin's group at UC-Davis CA USA that showed replacing $25 \%$ of urea-N with $\mathrm{N}$ from a mixture of 18 amino acids (AA) maximized the microbial yield (DM units/carbohydrate substrate units fermented), while adding a blend of protein AA plus peptides, doubled in vitro rumen microbial yield; further they found that adding AA mixtures, viz. mixed peptides, resulted in substantial reduction in proportions of individual AA into microbial protein derived from de novo synthesis [13].

The preceding hypothesis has been averred to earlier [14] where recommendation for dairy feeding stipulates that: 1) sufficient soluble and degradable proteins to dairy cows not exceeding rumen microbial protein requirements, 2) sufficient supplementary dietary protein with a high escape value and 3) the latter having an acceptable AA profile in order to supply absorbable protein, that would otherwise limit milk protein production.

The use of silage in the tropics, referring specifically to aquatic plants like wa- 
ter hyacinth, refers to a central concern of protein retention of the ensiled biomass and that previously the role of certain FAA has not come to fruition in explaining the intake response that is attributable to non-homeostatic control in nature where TYR is involved specifically as precursor to dopamine antagonizing serotonin for the hunger drive in that center while other FAA pertain to hormonal secretion of GHRH/GH leading to LBM accretion/fat loss and indirectly an increase in intake due to feedback to the CNS from innervation from the liver.

The factors in the rumen stomach of animal livestock have been elucidated and related to amino acids supplied as peptides and transported into the microbial cell and that are resynthesized as protein intracellularly with greater efficiency under optimal rumen fluid concentrations from feed protein microbial digestion and that leads to ruminal escape of that part of that feed fraction.

\section{Acknowledgements}

The author thanks with gratitude the management staff of Barberry House of Port Coquitlam, British Columbia Canada V3B1G3 providing premises where the author's home-based business is located.

\section{Conflicts of Interest}

The author declares no conflicts of interest regarding the publication of this paper.

\section{References}

[1] Flores, D.A., Phillip, L.E., Veira, D.M. and Ivan, M. (1986) Digestion in the Rumen and Amino Acid Supply to the Duodenum of Sheep Fed Ensiled and Fresh Alfalfa. Canadian Journal of Animal Science, 66, 1019-1027. https://doi.org/10.4141/cjas86-112

[2] Flores, D.A., Phillip, L.E., Veira, D.M. and Ivan, M. (1986) The Significance of Silage Protein Degradation and Plasma Amino Acid Ratios in the Control of Food Intake by Lambs Fed Ensiled and Fresh Alfalfa. Canadian Journal of Animal Science, 66, 1029-1038. https://doi.org/10.4141/cjas86-113

[3] Hardman, C.A., Herbert, V.M.B., Brunstorm, J.M., Munafo, M.R. and Rogers, P.J. (2012) Dopmamine and Food Reward: Effects of Acute Tyrosine: Phenylalanine Depletion on Appetite. Physiology and Behavior, 105, 1202-1207. https://doi.org/10.1016/j.physbeh.2011.12.022

[4] Bellone, J., Valetto, M.R., Aimaretti, G., Segni, M., Volta, C., Cardimale, G., Baffoni, C., Pasquino, A.M., Bernasconi, S., Bartolotta, E., Mucci and Ghigo, E. (1996) Effects of Phenylalanine, Histidine and Leucine on Basal and GHRH-Stimulated GH Secretion and on PRL, Insulin and Glucose Levels in Short Children. Comparison with Effects of Arginine. Journal of Pediatric Endocrinology and Metabolism, 9, 523-531.

[5] Sadiq, F., Cromptom, L.A., Scaife, J.R. and Lomax, M.A. (2008) Effect of Prolonged Intravenous Glucose and Essential Amino Acid Infusion on Nitrogen Balance, Muscle Protein Degradation and Ubiquitin-Conjugating Enzyme Gene Expression 
in Calves. Nutrition and Metabolism, 5, 5-14. https://doi.org/10.1186/1743-7075-5-5

[6] Flores, D.A. (2012) Erratum: Biotechnology and the Improvement of Silage (Tropical and Temperate) Rumen Digestion: a minireview. Applied Microbiology and Biotechnology, 94, 1399. https://doi.org/10.1007/s00253-012-4092-2

[7] Kellaway, R.C. and Leibholz, J. (1983) Effect of Nitrogen Supplements on Intake and Utilization of Low-Quality Forages. World Animal Review, 48, 33-37.

[8] Papas, A., Hatfield, E.E. and Owens, F.N. (1974) Responses of Growing Lambs to Abomasal Infusion of Corn Oil, Starch, Casein and Amino Acid Mixtures. Journal of Nutrition, 104, 1543-1553. https://doi.org/10.1093/jn/104.12.1543

[9] Gill, M. and Ulyatt, M.J. (2009) The Effect of Supplementation with Protein, Energy and L-Methionine, on the Digestion of Silage by Sheep. The Journal of Agricultural Science, 89, 43-51. https://doi.org/10.1017/S0021859600027180

[10] Flores, D.A. (1991) Biotechnology and the Improvement of Silage (Tropical and Temperate) Rumen Digestion: A Minireview. Applied Micobiology and Biotechnology, 35, 277-282. https://doi.org/10.1007/BF00172712

[11] Sharma, P., Teixeira de Mattos, J., Hellingwerf, K.J. and Bekker, M. (2012) Uncoupling of Substrate-Level Phosphorylation in Eschrichia coli During Glucose-Limited Growth. Applied Environmental Microbiology, 78, 6908-6913. https://doi.org/10.1128/AEM.01507-12

[12] Thompson, D.J. and Beever, D.E. (1980) The Effect of Conservation and Processing on the Digestion of Forages by Ruminants. In: Ruckebusch, Y. and Thivend, P., Eds., Digestive Physiology and Metabolism, AVI, Westport, Connecticut, 291-308. https://doi.org/10.1007/978-94-011-8067-2 14

[13] Broderick, G.A. (2011) Manipulation of the Dietary N-Fractions to Improve Ruminal Microbial Synthesis and Yield. US Dairy Forage Research Center, ARS, USDA. IFAS Extension, University of Florida, 81-88.

[14] Robinson, P.H. (2012) Rumen Escape Protein of Some Dairy Feedstuffs. UCCE University of California, Davis. Cooperative Extension. 